\title{
Os efeitos das situações de trabalho na construção do alcoolismo de pacientes militares da marinha do Brasil
}

\author{
Elizabeth Espindola Halpern ${ }^{1}$, Salette Maria Barros Ferreira ${ }^{2}$ e \\ João Ferreira da Silva Filho ${ }^{3}$ \\ Instituto de Psiquiatria da Universidade Federal do Rio de Janeiro
}

\begin{abstract}
O alcoolismo entre os militares passou a ser objeto de atenção especial na Marinha do Brasil a partir da criação do Centro de Dependência Química (CEDEQ), em 1997, quando se constatou que ele era um problema relevante na vida militar. Este artigo, por meio de uma pesquisa bibliográfica e de observações feitas com os pacientes do CEDEQ, analisa, criticamente, os fatores que participam na construção do transtorno alcoólico que os acomete. Os seus fatores determinantes parecem ir além dos relativos à sua dimensão intra-psíquica, abarcando questões referentes à própria instituição militar. Conclui-se que a fácil disponibilidade do álcool, sobretudo em razão da existência de uma cultura e tradição navais que são favoráveis ao seu consumo, facilitam o uso pesado.
\end{abstract}

Palavras-chave: Alcoolismo, Militares, Saúde do trabalhador, Condições de trabalho, Cultura.

The effects of the labor situations in the construction of the alcoholism of the brazilian's navy military patients

The alcoholism among militaries became a matter of special attention in the Brazilian Navy since the creation of the CEDEQ, in 1997, when it was considered a relevant problem in the military life. This article, based on bibliographic research and observations with patients of the CEDEQ, analyses, critically, the factors that take place in the construction of the alcoholic disease that affect them. The determining factors seem to go beyond those related to the military institution itself. It comes to the conclusion that the easy access to alcohol, particularly due to the existence of the navy tradition and its cultural aspects, which are favorable to its use, contribute to the heavy consumption.

Keywords: Alcoholism, Military personnel, Occupational health, Working conditions, Culture.

\section{Introdução}

$\mathrm{O}$ consumo pesado de álcool e o alcoolismo parecem fazer parte de um problema significativo da vida do militar da Marinha do Brasil, embora seja pouco discutido, inexistindo levantamentos e pesquisas que avaliem a sua dimensão. Dessa forma, os militares alcoolistas que fazem parte do Programa de Tratamento do Centro de Dependência Química (CEDEQ) do Hospital Central da Marinha (HCM) são uma fonte privilegiada de análise para se compreender algumas características do militar e da organização naval que possam contribuir para a ocorrência desse tipo de consumo prejudicial à saúde e ao desempenho das atividades. De acordo com os seus relatos nas sessões clínicas de grupoterapia, constata-se que o uso do álcool, muitas vezes, faz parte de uma tentativa de lidar com o estresse, com a ambivalência de condutas por parte de superiores, com a opressão vivenciada por eles em razão de temas como

\footnotetext{
1 Psicóloga. Doutoranda do Programa de Pós-Graduação em Psiquiatria e Saúde Mental doInstituto de Psiquiatria da Universidade Federal do Rio de Janeiro.

2 Doutora em saúde mental pela Universidade Federal do Rio de Janeiro. Professora Associada do Instituto de Psiquiatria da Universidade Federal do Rio de Janeiro.

3 Doutor em psiquiatria e saúde mental. Professor titular da Faculdade de Medicina da Universidade Federal do Rio de Janeiro. Instituto de Psiquiatria da Universidade Federal do Rio de Janeiro.
} 
hierarquia e disciplina, rigor, exigências, ameaças ou ocorrências de punições, entre outros. A disponibilidade do álcool e as oportunidades de beber ritualizadas, fazendo parte de um contexto idiossincrásico do ambiente naval, parecem contribuir para a edificação de uma cultura de trabalho que facilita a ocorrência do beber pesado e abusivo. Um aprofundamento sobre as características da cultura militar, que encorajam ou permitem práticas que conduzem a essas formas de beber, permitirá que se conheça melhor a questão no interior da Marinha, promovendo a abertura de debates e reflexões que poderão colaborar para a criação de uma política de prevenção e de tratamento que permita atender às necessidades individuais e institucionais.

\section{A emergência do alcoolismo na modernidade}

A presença do álcool ao longo da história da humanidade assumiu diferentes formas, ficando à mercê da ação dos vetores sociais, políticos, econômicos e culturais que, agindo em conjunto, foram determinando uma relação singular dos sujeitos com o álcool. Embora tenha sido constatada a massificação de seu consumo na Idade Moderna, o envolvimento do homem com o álcool sempre esteve presente na história da civilização de diferentes formas, atrelado a hábitos, crenças e práticas individuais.

A simbologia e os significados das bebidas em cada sociedade, e mesmo em cada época, estiveram sempre vinculados às esferas da sensibilidade humana. Ou pelo lado das práticas místicas e religiosas, ou pelo lado das sensações de bem-estar e de prazer (Santos, 2006, p. $65)$.

Mudanças paradigmáticas, ocorridas a partir de transformações na conjuntura e no pensamento vigentes, alteraram o significado do álcool na vida dos sujeitos. Na realidade, foi necessário percorrer um longo "trajeto epistemológico" para que o alcoolismo pudesse assumir o atual caráter mórbido. A criação desse quadro nosológico foi viabilizada dentro de um contexto em que outras doenças também foram identificadas, a partir de uma medicina que emergiu a partir do Renascimento. Conforme Luz (1992) esclarece, trata-se de uma racionalidade médica, cujos pilares se alicerçam em paradigmas oriundos desse momento histórico e que ainda se faz presente na atualidade, afetando as práticas, os saberes e as instituições de saúde. De um modo geral, as racionalidades médicas fundamentam-se em cosmologias, que são determinadas concepções de como as coisas e o mundo se organizam. Portanto, todo o sistema médico complexo, inclusive o ocidental contemporâneo, está fundamentado em uma cosmologia e, aquela que a embase, embora de maneira implícita, é fortemente influenciada pela física clássica newtoniana, cujo paradigma é o biomecânico, ou seja, o homem sendo visto como máquina. Segundo Kuhn (1991): "Um paradigma é aquilo que os membros de uma comunidade partilham e, inversamente, uma comunidade científica consiste em homens que partilham um paradigma" (p. 218). Adicionalmente, ainda a respeito da noção de paradigma, Luz (1996) assinala:

De acordo com Kuhn, paradigma é análogo a um mapa que norteia e governa a percepção, as perguntas e os procedimentos do cientista diante de seu objeto de conhecimento; ou como uma lente que permite configurar e ordenar certos fatos de uma realidade que, em si mesma é infinita. Um outro mapa, uma outra lente, ou seja, um outro paradigma produziria uma configuração diferente da realidade e, conseqüentemente, uma outra ciência (p. 11).

Dessa forma, graças à presença de uma determinada "lente" é que foi possível a sua constituição, o alcoolismo passou a ser a enquadrado como uma categoria nosológica quando a 
emergente medicina contemporânea pode identificá-lo como tal. "Da mesma forma que seus pacientes, um médico vê o mundo através do filtro de suas representações: só que o imaginário médico está sempre protegido pelo escudo da racionalidade científica" (Camargo Júnior, 1992, p. 218). Assim sendo, práticas e saberes vão sendo reproduzidos em instituições de ensino e em espaços de exercício profissional, sedimentando uma forma de se ver, enquanto profissionais, e de agir.

\section{A dimensão sociocultural do alcoolismo}

A investigação a respeito do significado do alcoolismo, mais do que uma simples adicção, remete à necessidade de se realizar um entendimento sobre qual insatisfação ou malestar encontra-se em pauta. A percepção da existência de uma dimensão sociocultural, viabiliza o alcance de uma maior esfera de compreensão sobre seus processos, podendo ser conceituada como uma toxicomania, ou seja, o uso, abuso e dependência de substâncias psicoativas podem refletir uma problemática social e cultural, além de serem compreendidas pelo seu aspecto médico e legal. Assim, ela seria compreendida como um discurso, conforme estabelece Silva Filho e Luce (2001):

A toxicomania seria um fenômeno diretamente proporcional ao avanço do desenvolvimento de uma nova forma de sociabilidade, como um modelo estrutural de sintoma social que opera nos indivíduos em sua relação com os outros objetos. (...) A toxicomania é o paradigma de nossa sociedade de consumo, é a sua verdade. Ela não é apenas um problema singular, mas sim um fenômeno sócio-cultural importante (p. 68).

Esse enfoque permite a ampliação das possibilidades de intervenção pois, mais do que se propor uma solução jurídica ou médica, admite-se a implementação de ações sociais, econômicas e culturais. Em oposição à tendência secular da racionalidade médica contemporânea ocidental, pautada em uma vocação diagnóstica, o fenômeno das toxicomanias requer um entendimento que considere o indivíduo de forma integral, incluindo o meio que o afeta e, conforme Cruz e Ferreira (2001) salientam, é um fenômeno marcado pela complexidade, sendo fundamental que se realize um enfoque de sua dimensão sociocultural. Portanto, cada vez mais se atribui um peso maior ao contexto de sua emergência e produção, quando se pretende pensar sobre a questão da dependência química e, em particular, do alcoolismo, o que representa uma mudança paradigmática fundamental a respeito deste conceito.

Esse tipo de olhar exige que se debruce sobre o tema da toxicomania com uma proposta investigativa que inclua não apenas os fatores determinantes do indivíduo, como também os aspectos externos a ele. Portanto, neste estudo, pretende-se discutir a participação dos elementos institucionais que podem ter participado da construção do transtorno alcoólico dos pacientes do CEDEQ, em especial à disponibilidade do álcool em razão da cultura e tradições navais.

\section{CEDEQ: um lugar para ver e ouvir o alcoolista}

A pessoa, quando recai, vem com juros e correção monetária (paciente do CEDEQ). 
Os militares, que são pacientes alcoolistas do CEDEQ, surgem no cenário naval como porta-vozes de uma realidade que permaneceu à margem da percepção das autoridades navais até a sua criação em 1997. Até então, o consumo abusivo e a dependência do álcool constituíam um problema restrito ao usuário. As providências que eram tomadas pela organização naval quando um militar se apresentava bêbado a bordo eram variadas (e ainda são), oscilando entre as posições extremas da punição até sua negação. $\mathrm{O}$ reconhecimento de que o alcoolismo e a dependência química são um problema para a instituição naval brasileira teve como marco a criação do CEDEQ. Contudo, não parece existir um reconhecimento de que a própria Marinha possa ter uma responsabilidade na construção destes transtornos.

O CEDEQ é um centro pioneiro, nas Forças Armadas brasileiras, para o tratamento ambulatorial a dependentes químicos. A sua criação representa a constatação de que a dependência química existe no meio militar e que exige atenção especial e diferenciada. Anteriormente, esta clientela era assistida por psicólogos e psiquiatras na Unidade Integrada de Saúde Mental (UISM), sem que houvesse um atendimento especializado e sistematizado. O CEDEQ realiza atendimento ambulatorial, em grupo, com a duração mínima de um ano, realizado por uma equipe multiprofissional, com formação em psicologia, psiquiatria e serviço social.

O CEDEQ possui um Programa de Tratamento da Dependência Química, constituído por cinco fases: Grupo Motivacional, Fases I, II, III e o Grupo de Consolidação. Cada fase possui um número mínimo de sessões e de atividades a serem cumpridas, de acordo com o que reza o contrato de tratamento assinado pelo paciente ao ingressar no programa.

O Grupo Motivacional corresponde à primeira fase ou etapa do programa de tratamento, visando promover a sua adesão à ele, ampliando a conscientização do indivíduo a respeito da dependência química, minimizando o grau de negação. Esta fase possui um mínimo de trinta encontros, com a freqüência de duas sessões semanais, totalizando quatro horas semanais. Nesta etapa, objetiva-se propiciar ao paciente o conhecimento do $1^{\mathrm{O}}$ passo dos Alcoólicos Anônimos e Narcóticos Anônimos: "Admitimos que éramos impotentes perante o álcool (outras substâncias ou pessoas) e que tínhamos perdido o domínio sobre nossas vidas". Leituras são feitas a este respeito, tais como: "Viver Sóbrio" e "Os Doze Passos e as Doze Tradições", publicações dos Alcoólicos Anônimos, bem como são vistos filmes, tais como: "O valor da vida", "Dose de esperança" e o "Diário de um adolescente", seguidos de debates.

A Fase I tem por objetivo auxiliar o indivíduo alcançar a abstinência do álcool e drogas, estabelecer a relação do abuso de drogas com as repercussões negativas nas diversas áreas da vida do indivíduo, conhecer o 2oㅡㄴ 3o e o 4o passos dos Alcoólicos Anônimos, cujos conteúdos são aprofundados a partir de leituras e debates. Deste modo, enseja-se incentivar mudanças de hábitos e de atitudes, assim como o envolvimento com a família no tratamento. Esta etapa possui um número mínimo de dezoito sessões, com duas horas cada, duas vezes por semana. Filmes como os que se seguem servem para reflexão e debate: "Drogas e sua ação no SNC", do NEPAD, "Farrapo humano", "A fronteira invisível" e "A cocaína de HaightAshbury".

A Fase II tem por meta a manutenção da abstinência de álcool e drogas, conhecer o $5^{\circ}$ 6ำ o e $8^{\mathrm{o}}$ passos dos Alcoólicos Anônimos e empreender mudanças que promovam melhoria da qualidade de vida, ao longo de um número mínimo de 18 sessões, com duas horas cada, duas vezes por semana. Filmes para reflexão e debate são passados, como: "Despedida em Las Vegas", "Feitiço do tempo" e "Vinte e oito dias", "Quem mexeu no meu queijo" e o "Segredo".

A Fase III visa a manutenção da abstinência de álcool e drogas, dando ênfase aos passos $9^{\circ}, 10^{\circ}, 11^{\circ}$ e $12^{\circ}$ passos e a ampliação do autoconhecimento. Além de aprofundar os conteúdos dos livros já citados, filmes como os que se seguem são apresentados para debate: "Degradação humana", "Vem dançar comigo", "Endiabrado", "O amor é cego" e "A corrente do bem". 
Adicionalmente, todos os pacientes devem assistir a cinco aulas, que são realizadas uma vez por mês, no auditório do HCM, ministradas pela equipe do CEDEQ. As aulas são sobre os seguintes temas: "Substâncias Psicoativas I", "Substâncias Psicoativas II", "Alcoolismo", "Tabagismo" e a "História do Alcoólicos Anônimos e os 12 Passos". Por fim, o Grupo de Consolidação tem por objetivo oferecer ao paciente que concluiu o Programa de Tratamento da Dependência Química, a continuidade do tratamento, visando a consolidação de sua abstinência e o aprofundamento sobre temas correlatos que possam ser relevantes ao seu fortalecimento pessoal, em todas as esferas de sua vida. Nesta etapa, não há um número prédeterminado de sessões e a freqüência é de uma vez por semana, com sessões com a duração de duas horas.

Todas as Fases do programa têm por meta estimular o paciente a desenvolver uma maior consciência da necessidade de entrar em abstinência, despertar a responsabilidade pela sua recuperação e minimizar o grau de negação sobre sua situação. Adicionalmente, visam promover, a partir dessa mudança de mentalidade e de atitude, uma maior adesão ao tratamento e participação nas atividades propostas, bem como a diminuição do absenteísmo.

O programa segue o Modelo Minnesota, tem como base a terapia cognitivocomportamental, fazendo uso dos 12 Passos dos Alcoólicos Anônimos. A base do tratamento é a abstinência completa e o foco do desenvolvimento do tratamento é a mudança de estilo de vida. A manutenção do tratamento depende de uma adequada socialização, portanto, acreditase que a reabilitação dependerá do apoio de sistemas naturais como a família, amigos e grupos de ajuda-mútua. Adicionalmente, o tratamento atem-se a uma intervenção que prevê um processo contínuo, que engloba o conceito de recuperação e não a cura imediata assim que a intervenção termina. A concepção de adoecimento é vista como crônica e multicausal. Logo, o tratamento do indivíduo se baseia em uma abordagem biopsicossocial que sirva de suporte para o indivíduo ao longo da sua vida. Portanto, a intervenção se volta para a causa que desencadeia o processo e não para a predisposição à dependência. Por fim, a abordagem é multidisciplinar, existindo um suporte médico e psiquiátrico para problemas co-existentes, assim como é feita testagem toxicológica periódica, com fins terapêuticos.

Embora a iniciativa de se criar o CEDEQ tenha especial significado por reconhecer que o alcoolismo é um problema no interior da Marinha, este transtorno ainda é pouco conhecido e reconhecido como tal entre os próprios militares, com ações tímidas diante da magnitude e efeitos do problema das drogas e, em particular, do alcoolismo.

\section{A ótica da Marinha brasileira sobre o alcoolismo: o beber social}

Ao se abordar a temática do alcoolismo na Marinha é preciso esclarecer, de antemão, como ela tende a ser percebida, de uma forma geral, no seio institucional. Na realidade, a noção do alcoolismo como doença ainda se encontra em processo de difusão e de assimilação. Porém, a percepção mais profunda do complexo processo de sua construção, reconhecendo-se a participação dos vetores sociais, culturais, econômicos e históricos envolvidos, é uma etapa mais avançada a ser atingida, requerendo, provavelmente, uma mudança da mentalidade institucional, em particular no que diz respeito aos conceitos de saúde e de doença.

É remota a idéia de que possa existir uma construção social desta dependência, com a participação da própria instituição. A noção de que a realidade possa vir a ser construída socialmente, conforme a sociologia do conhecimento se propõe a estudar (Berger \& Luckmann, 1985), abriria uma dimensão mais ampla sobre os processos que facilitam a construção do alcoolismo, fomentados direta ou indiretamente por esta instituição. É mais fácil reconhecer a existência de um sujeito problemático, que precisa ser tratado ou afastado, como se ele fosse 
um elemento distinto que não fizesse parte deste conjunto, mantendo a estrutura naval intocável, quando, na realidade, ele é indissociável dela. Por conseguinte, como isto não é levado em conta, o foco da questão da dependência química se mantém centrado no sujeito, prevalecendo a visão de que ele é um "mau" bebedor. A partir desta ótica, bastaria que ele fosse punido e afastado do epicentro da administração naval, sobretudo das funções operativas, ou ainda, que fosse encaminhado ao CEDEQ, com a expectativa de que seu problema fosse resolvido.

\section{Disponibilidade do álcool e cultura do trabalho naval}

Nas forças armadas americanas, pesquisas têm constatado que o uso pesado de álcool entre os militares é um problema significativo, geralmente, feito para lidar com o estresse, a solidão, o tédio e a ausência de outras atividades recreativas. A fácil disponibilidade do álcool, das oportunidades ritualizadas e de políticas inconsistentes, contribuem para uma cultura no trabalho que facilita o seu consumo pesado e abusivo (Ames \& Cunradi, 2005).

Embora as rações de álcool tenham sido abolidas na marinha real inglesa em 1970, quebrando uma tradição que teve seu início com a distribuição de ração diária de rum a bordo dos navios ingleses no século XVII, em razão de sua melhor conservação se comparada à da água e da cerveja (Pack, 1982/1995), o beber continua a representar um papel de destaque na vida do contingente militar naval. Outro fator que deve ser destacado é que o seu consumo não é permitido a bordo dos navios americanos, exceto em raras ocasiões, em cerimônias de despedida em homenagem a um oficial de alta patente para a reserva, sendo limitado a duas cervejas por membro da tripulação. A disponibilidade de álcool discutida nas pesquisas no universo naval militar dos EUA tem como referência as oportunidades de beber em portos, nas horas de lazer e nos licenciamentos (fora das horas de trabalho) (Moore et al., 2007).

A questão que se refere à cultura do trabalho naval e à disponibilidade do álcool é ressaltada por Ames e Cunradi (2005) em sua pesquisa sobre os problemas relacionados ao uso do álcool entre jovens militares americanos. No que se refere à cultura do trabalho, pesquisas já demonstraram que grupos que trabalham juntos desenvolvem crenças compartilhadas e práticas que influenciam o consumo do álcool (Trice \& Sonnenstuhl, 1990; Ames \& Janes, 1992 citado por Ames \& Cunradi, 2005).

A cultura organizacional militar pode representar um fator de risco para o uso pesado do álcool, pois este tipo de cultura pode influenciar crenças entre os militares sobre a admissão da existência de certos contextos como sendo aceitáveis para o consumo do álcool, incluindo rituais de beber com colegas de trabalho antes, durante ou após o expediente. Adicionalmente, esta cultura pode alimentar crenças sobre o comportamento do beber, como a quantidade a ser ingerida, a demonstração pública dos efeitos do álcool, o envolvimento em brigas, enfrentamento com supervisores, adormecer durante o expediente e trabalhar com "ressaca" (Ames, Grube \& Moore, 1997).

Além disso, este tipo de cultura do trabalho pode trazer expectativas sobre as conseqüências positivas ou negativas do beber (Grube, Ames \& Delaney, 1994). Ames et al. (2004) também estudaram a influência da cultura do trabalho nas práticas do beber em várias bases militares da Marinha americana, quando foi possível verificar a existência de rituais e de rotinas de beber, bem como elementos do ambiente do trabalho que encorajam o beber em serviço, em bases de terra e durante os licenciamentos (deployment liberties) por ocasião do desembarque. Jovens marinheiros percebem o beber com seus colegas de trabalho durante a jornada de trabalho semanal como um mecanismo apropriado para lidar com o estresse, tédio, solidão e ausência de outras atividades de lazer. De acordo com os entrevistados nesta pesquisa, o consumo pesado equivaleria à ingestão de cinco drinks ou mais para homens e quatro drinks ou mais para mulheres, por ocasião, e o abuso (binge), equivalendo a cinco drinks ou mais para 
homens e quatro drinks ou mais para mulheres, dentro do período de duas horas. Segundo eles, faz parte da tradição cultural naval o beber pesado e o comportamento permissivo para o beber após o expediente, inclusive a liberdade de beber durante o licenciamento. No licenciamento, o beber permissivo e o beber até o ponto de alcançar a intoxicação não são, necessariamente, vistos como inadequados ou passíveis de punição, a menos que eles se encontrem intoxicados a ponto de não conseguirem voltar para o navio na hora determinada (Ames \& Cunradi, 2005).

Acredita-se que o fator chave que age como facilitador na cultura ocupacional, tanto no passado quanto na atualidade, é a pronta disponibilidade do álcool a seus integrantes. A literatura confirma a clara relação entre o fácil acesso e as altas taxas de consumo e os problemas reportados pelo uso de álcool. No que tange à disponibilidade do álcool, a sua disponibilidade física e social podem influenciar o beber pesado e o uso abusivo entre adultos jovens militares. A disponibilidade do álcool é conhecida como um fator de risco para o aumento do uso do álcool na população em geral (Gruenwald, Millar \& Treno, 1993) e nos locais de trabalho (Ames \& Grube, 1999). Ames et al. (2004) apontam que os militares da Marinha americana entrevistados reportaram que o álcool e as oportunidades para beber eram facilmente acessíveis, tanto nos portos estrangeiros, quanto nas bases americanas dos EUA, nos bares, nos quartéis ou nos quartos dos hotéis próximos às bases militares. Nos portos estrangeiros, o acesso ao álcool é facilitado pelo seu baixo custo, os bares encontram-se próximos do local de desembarque, o número de portos com leis proibindo o consumo para os menores de idade são reduzidos e muitos marinheiros que desejam beber organizam grupos para este fim antes do desembarque. Outros achados demonstraram que a disponibilidade, tanto social como física do álcool, para jovens militares da Marinha americana incluem: preços baixos oferecidos nas lojas das bases navais (navy exchange base stores), as freqüentes festas nos quartéis, as vendas promocionais nos bares em torno das bases e as múltiplas oportunidades para os menores de idade, a despeito das limitações de idade estabelecidas nas compras de álcool e dos esforços oficiais para desestimular o seu uso na marinha americana (Moore, Ames \& Cunradi, 2007).

A disponibilidade física se refere não apenas à extensão em que o álcool encontra-se disponível em um certo ambiente, mas também às barreiras ou custos associados à sua obtenção. A existência de leis e de outras políticas, incluindo os regulamentos militares, oferece uma variedade de restrições sobre aqueles que podem comprar ou consumir álcool, sobre o quanto pagarão por ele, e sobre quando e onde poderão comprá-lo ou bebê-lo. A disponibilidade física pode ser subdividida em objetiva e subjetiva. A objetiva se refere aos fatores legais, organizacionais e geográficos que afetam os custos em tempo ou dinheiro para adquirir o álcool. Quanto aos subjetivos, referem-se à percepção destes fatores, incluindo crenças sobre a facilidade ou dificuldade de obter o álcool. Por sua vez, a disponibilidade social relaciona-se com o grau de apoio normativo em prol ou contra o beber em cada ambiente. Este item também pode ser subdividido em disponibilidade social objetiva e subjetiva. A objetiva corresponde às formas de beber da família, amigos e da sociedade; a subjetiva, às percepções pessoais sobre as normas do beber em um certo meio. Nessa perspectiva, verifica-se que existe um profundo enraizamento das tradições culturais que apóiam a disponibilidade física e social do álcool nos ambientes de trabalho e social (Moore et al., 2007).

Na Marinha do Brasil, o consumo do álcool a bordo é uma questão muito difícil de ser abordada, fazendo parte da cultura marinheira. O uso leve e moderado é bem aceito e não há uma percepção nítida de que ele possa sequer gerar acidentes e incidentes no trabalho quando consumido durante ou após o expediente. Desconhece-se o quanto os bebedores, leves e moderados, estão sujeitos a sofrerem acidentes ou a provocarem incidentes (violência, acidentes, absenteísmo e a perda de produtividade) no trabalho, levando-se em conta que $70 \%$ a $80 \%$ dos incidentes relacionados ao uso de álcool ocorrem entre os consumidores leves e moderados (Fauske, citado por Vaissman, 2004). Na realidade, observa-se que o uso abusivo do álcool e o próprio alcoolismo não são identificados sob uma ótica médica, senão quando se 
encontram em um estágio avançado, comprometendo de forma ampla a vida do sujeito. Geralmente, percebe-se que o militar "passou dos limites" ou "abusou", como se fosse uma inabilidade circunstancial circunscrita a uma determinada ocasião na qual ele não "soube" beber. Esse "deslize" seria um fato isolado, ou ainda, faria parte de uma "fase" ruim na sua vida, após a qual tudo "voltaria ao normal". Eis porque muitos deixam de perceber a proximidade deste transtorno, dificultando ações preventivas e educativas, pois não se sentem implicados no problema. O comparecimento dos militares às palestras preventivas feitas pelo CEDEQ é, geralmente, por ordem (compulsória), com uma participação irrisória de oficiais. Muitos militares temem comparecer espontaneamente e serem, por isso, olhados com suspeita, como se a sua mera presença e participação pudessem denunciar o seu envolvimento com uma substância. Contudo, acredita-se que, além daqueles que freqüentam o CEDEQ, devam existir muitos outros toxicômanos, com diferentes graus de comprometimento e de envolvimento, prováveis alvos de atenção, sobretudo das ações preventivas. No futuro, talvez a administração superior desperte o seu interesse para fazer um levantamento do percentual afetado, inclusive de oficiais, talvez pelo emprego de exames toxicológicos, no ingresso, aleatoriamente ou nas inspeções periódicas.

Ainda que não se conheça numericamente a extensão do problema das drogas na Marinha e, em particular, do alcoolismo, pelos relatos dos pacientes, constata-se que a instituição naval cultiva uma cultura que é simpática e favorável ao consumo do álcool. Destacam-se, pois, como principais razões para a facilidade de beber álcool na Marinha a existência de uma cultura e tradições que sustentam esses hábitos e práticas de beber, a existência de políticas ambivalentes e de normas favoráveis que apóiam crenças em prol do consumo no ambiente de trabalho, ou seja, a existência de uma cultura favorável no espaço do trabalho, a disponibilidade do álcool, a perpetuação de falsas concepções sobre o hábito de beber e sobre o alcoolismo, amparadas por mitos e distorções perceptivas, obviamente a favor de seu consumo, introduzidas aos recém-ingressos, disseminadas no cotidiano e sendo compartilhadas e reproduzidas pela tripulação naval. Por meio dos relatos dos pacientes, verifica-se que o álcool é a substância psicoativa mais presente no dia-a-dia naval, fazendo parte da cultura marinheira. O seu consumo é, geralmente, estimulado, desde que ocorra dentro dos códigos tacitamente estabelecidos, como se verifica nos almoços às sextas-feiras, acompanhando uma feijoada ou dobradinha, nos coquetéis, nas comemorações, nas solenidades, nas promoções e nos fecha-ranchos (almoços tradicionais). Uma percepção mais ampliada sobre os prejuízos que o álcool é capaz de provocar parece ser bloqueada por uma forte mentalidade favorável ao seu consumo, encontrando-se francamente arraigado, não apenas nos hábitos, mas, sobretudo, no imaginário da tripulação marinheira, imerso na sua cultura e tradições navais.

A idéia de haver um beber social pode funcionar não só como um escudo para o indivíduo, como também para a instituição. Em contraposição a esta idéia, surge a imagem do dependente do álcool, amalgamada à do bêbado claudicante, tranqüilizando muitos sujeitos no sentido de acreditarem que o seu beber não é como o dele, mas é apenas "social". Na organização naval, todos bebem: socialmente! De acordo com o senso comum, a distinção precisa entre o bêbado e o bebedor social pode parecer elementar, como se fizessem parte de grupos estanques. A visão caricata do bêbado parece tranqüilizar o bebedor, leve ou moderado, como se pudesse garantir a existência de uma demarcação precisa entre ele e o etilista: "Eu não posso ser um alcoólatra, eu nem bebo todo o dia!" (Paciente do CEDEQ).

\section{A classe e o habitus das praças alcoolistas do CEDEQ}

Cabe destacar que a totalidade dos pacientes do CEDEQ pertence à classe das praças (marinheiros, soldados, cabos, sargentos e suboficiais), pois não há oficiais em tratamento, 
sobretudo por não procurarem auxílio. Essa noção de classe será aplicada segundo a concepção de Bourdieu (2007) quando se refere aos:

(...) conjuntos de agentes que ocupam posições semelhantes e que, colocados em condições semelhantes e sujeitos a condicionamentos semelhantes, têm, com toda a probabilidade, atitudes e interesses semelhantes, logo, práticas e tomadas de posição semelhantes (p. 136).

Segundo o autor, os agentes (indivíduos) ocupam um espaço de relações, que é tão real como um espaço geográfico. Os agentes ou grupos de agentes são definidos por suas posições relativas neste espaço, não sendo possível ocuparem duas posições opostas, sendo submetidos a um campo de forças, impostas a todos os que entram nele. Os agentes são distribuídos no campo social, ou seja, em um espaço multidimensional de posições, conforme o volume global do capital que possuem e seu peso relativo das diferentes formas de suas posses. O capital pode ser econômico, cultural, social e simbólico. Essas posses podem se expressar pelas vias econômica, cultural ou social, por meio de títulos (por exemplo, escolares e de nobreza). A posição de um determinado agente no espaço social pode ser definida pela posição que ele ocupa nos campos.

Por sua vez, a classe das praças poderá ser mais bem compreendida e, em particular, a classe daquelas que são pacientes alcoolistas do CEDEQ, ao se verificar que seus integrantes encontram-se alocados em um espaço submetido a um campo de forças, não exatamente por sua escolha, mas obedecendo a uma série de fatores inerentes a um jogo que se faz presente em um espaço de relações. Embora as praças do CEDEQ encontrem-se munidas de parcos montantes de capital, este lhes confere uma posição neste cenário, sobretudo no que concerne ao capital simbólico. Este tipo de capital é apresentado por ainda que de desprestígio, como sendo constituído de elementos tais como prestígio, reputação, fama, entre outros. Por conseguinte, as praças, em contraste com os oficiais, têm pouco desse capital.

Acredita-se que possa estar em pauta um jogo sutil relativo à luta ou à manutenção de posições sociais, provocando sentimentos de superioridade e de inferioridade que possam responder por comportamentos e atitudes discrepantes entre as diversas classes no âmbito da Marinha. A origem social ainda determina o lugar de cada indivíduo na sociedade e, no caso das praças, o seu lugar na estrutura naval. Processos de valorização e de anulação que atravessam continuamente as relações sociais encontram-se em ação, ainda que inconscientemente. A classe específica de alcoolistas do CEDEQ também parece servir à constituição deste campo de forças.

Ainda segundo Bourdieu (2007), existe ainda uma importante relação dialética entre a sociedade e o sujeito, ou melhor, entre o campo e o habitus individual, socialmente determinado, ambos em processo de transformação. Nesta ótica, as ações, comportamentos, escolhas ou aspirações individuais resultariam da relação entre um habitus e os aspectos conjunturais. O habitus seria uma matriz de percepções, de apreciações e de ações, produto de trajetórias anteriores, mas também é adaptação. O habitus surge como um conceito capaz de conciliar a oposição aparente entre a realidade exterior e as realidades individuais, ou seja, entre os mundos objetivo e subjetivo das individualidades, demonstrando a interdependência entre o indivíduo e a sociedade, adquirido nas e pelas experiências práticas, permanentemente voltado para as funções e ações do agir cotidiano. Em suma, de acordo com Bourdieu (2007), "(...) o habitus, como indica a palavra, é um conhecimento adquirido é também um haver, (...) indica a disposição incorporada, quase postural” (p. 61). Como instrumento conceitual, o habitus permite a apreensão de uma certa homogeneidade nas inclinações, nos gostos e preferências de grupos e de indivíduos que têm uma mesma trajetória social. Este instrumento será útil neste estudo ao se analisar o habitus dos pacientes em pauta, superando visões deterministas. Objetiva-se conhecer o habitus daqueles que têm uma identidade, que é social, forjada pela interação de distintos ambientes, montada a partir de um processo de estímulos plurais, heterogêneos e, muitas vezes, incoerentes. Sobretudo, objetiva-se identificar a 
existência de um habitus alcoólico que é progressivamente sedimentado entre os militares, fruto de aspectos que são idiossincrásicos da vida e cultura navais, afetando, inclusive, suas identidades.

\section{As praças: a dimensão de sua vulnerabilidade ao alcoolismo}

Ao longo dos dez anos de existência do CEDEQ o número de oficiais que participou do Programa de Tratamento da Dependência Química foi próximo de zero. Na verdade, mesmo nas palestras preventivas ministradas pela equipe nas diversas Organizações Militares (OM) da Marinha, a presença do oficialato é reduzida, enquanto que a de praças é maciça, sobretudo porque comparecem a estes eventos por ordem de seus superiores. Vaissman (2004) assinala que os programas de dependência química nas empresas normalmente não atingem os níveis mais elevados da hierarquia, apenas os menos qualificados, que são mais sujeitos às sanções disciplinares nas empresas. Talvez, por essa razão, Kotshessa (citado por Vaissman, 2004) considere que o seu consumo represente uma forma do trabalhador lidar com as contradições institucionais.

A alcoolização aparece ligada ao processo de industrialização de forma contraditória, já que o mesmo processo que a gera vai precisar combatê-la. O álcool é justamente utilizado pelos trabalhadores como meio social para fazer frente às normas laborais que, por sua vez, lhes facilita reiterar pautas pré-industriais de trabalho (Vaissman, 2004, p. 34).

As praças são um grupo menos prestigiado na Marinha, formado por indivíduos com menor escolaridade (na maior parte das vezes) e soldo (salário) e que, em geral, exercem tarefas menos complexas na organização militar. Seligmann-Silva (1995) assinala que as situações de risco para o alcoolismo encontram-se associadas, sobretudo, à existência de atividades socialmente desprestigiadas, quando a possibilidade de qualificação ou de ascensão profissional é restrita, por envolverem atos ou materiais considerados desagradáveis ou repugnantes. A despeito da existência destas situações de risco, a produção do alcoolismo é, geralmente, atribuída ao usuário do álcool.

(...) conforme assinalam Chavrot e Dejours, tanto as teorias adotadas pelos serviços de medicina do trabalho das empresas, como as informações transmitidas aos trabalhadores, em cursos ou por outros meios, estão geralmente centradas e dirigidas para uma culpabilização do trabalhador. (...) Chega-se, assim, a diluir totalmente a responsabilidade pelas condições de trabalho, forma pela qual se obtém a produtividade, sendo que isto ocorre em toda uma série de afeç̧ões, onde os praticantes da medicina constatam que certas categorias de trabalhadores são particularmente atingidas (Seligmann-Silva, 1990, pp. 226-227).

Uma sistemática aplicada que é bastante peculiar da organização naval e que gera tensão constante, sobretudo às praças, diz respeito à avaliação semestral, em vários quesitos, aplicada a todos os militares. Nessa ocasião, o militar recebe um conceito numérico, de 1 a 5 , sendo que o conceito 5 expressa a sua excelência, favorecendo-o para obter futuras promoções e melhores comissões, ou seja, o exercício profissional em locais e atividades de maior prestígio e benefício para sua carreira. Conceitos de 1 a 3 são dados àqueles que têm baixa pontuação semestral, muitas vezes sendo atribuídos aos que cometeram contravenções disciplinares, conforme discriminadas no Regulamento Disciplinar para a Marinha (RDM) ${ }^{4}$. A título de ilustração, é contravenção disciplinar, conforme prevista no artigo $7^{\circ}$, item 12 , do RDM "retirar-se da presença do superior sem a sua devida licença ou ordem para fazê-lo" (Brasil,

4 O Regulamento Disciplinar para a Marinha tem por propósito a especificação e a classificação das contravenções disciplinares e o estabelecimento das normas relativas à amplitude e à aplicação das penas disciplinares, à classificação do comportamento militar e à interposição de recursos contra as penas disciplinares. 
1983), cabendo a aplicação de penas disciplinares, como a repreensão ou prisão, dependendo do julgamento do comandante da organização militar.

$\mathrm{Na}$ realidade, o que se observa é que o RDM é muito mais freqüentemente e rigorosamente aplicado às praças do que aos oficiais, a despeito da importância desta classe de profissionais na organização naval, sendo, na realidade, a sua base de sustentação. As praças, que são usuárias de álcool, geralmente são punidas ou, em casos extremos, desligadas do Serviço Ativo da Marinha (SAM). Os oficiais, por sua vez, quando são punidos, não o são ostensivamente, seus erros são absorvidos com discrição e seus excessos alcoólicos são minimizados e perdoados, sendo poupados das sanções administrativas. Na realidade, parece não haver um critério de aplicação geral a ser conduzido, muito pelo contrário, parece existir uma variedade de respostas da administração naval, com o emprego de procedimentos aleatórios, ora aplicando-se a lei, ora incentivando seu consumo, ora encaminhando o usuário para tratamento, ora desligando-o do SAM, acentuando-se as diferenças de tratamento e de abordagem entre os grupos das praças e dos oficiais

De acordo com as observações clínicas feitas nas sessões de grupoterapia, a aplicação (ou a possibilidade de aplicação) de sucessivas penas às praças e, em particular, aos alcoolistas do CEDEQ, justas ou injustas, abusivas ou não, parece produzir um achatamento progressivo de suas subjetividades, afetando seu desempenho e saúde global, incluindo orgânica e psíquica, rebaixando a sua autoconfiança e auto-estima, convidando-os a errar mais ainda. Gaulejac (2006) entende que "(...) o alcoolismo é um meio de viver com a vergonha, entretendo-a" (p. 18). Segundo seus relatos, o alcoolismo entre estes militares parece surgir ou se desenvolver neste contexto, afetando a sua própria subjetividade. Um aspecto que demonstra esta vertente refere-se ao momento em que ele, ao ingressar na vida militar, recebe um número que o identificará, o NIP, um número de inscrição pessoal. No caso das praças, este número antecede o nome, ou melhor, o nome de guerra (geralmente formado de um sobrenome), indicando, ainda que sutilmente, que o número tem precedência sobre o próprio nome do sujeito. Paulatinamente, na trajetória de tornar-se militar, sua identidade vai sendo substituída por um número de corpo, ou seja, um corpo que não corresponde ao seu organismo. $\mathrm{O}$ militar sempre faz parte de algum corpo (conjunto, grupamento), "Corpo da Armada", "Corpo dos Fuzileiros", "Corpo de Aspirantes", tendo que construir uma nova noção de corpo, sendo que ele é uma célula desse outro corpo. Portanto, ele passa a ser um NIP, passível de controle, de avaliação e de sanções. Dentre outras formas de controle, sobressai a avaliação semestral, conforme foi citado anteriormente, segundo critérios dispostos em um manual, contendo os elementos que são esperados de um bom militar, atribuindo-se valores para cada quesito. São estratégias que parecem implicar em um reducionismo do seu eu, visando à uniformidade da tropa, sem que haja um interesse específico no indivíduo que ali se encontra.

Atingido pela vergonha, o alcoólico poderá experimentar uma vivência de decadência, "privada" e "pública". Gaulejac (2006) esclarece que na decadência "privada", surge uma imagem de um Eu incapaz, medíocre e impotente, passando a ter vergonha de si mesmo. Na decadência "pública", a vergonha de si mesmo seria produzida pelo olhar do outro, que traria uma avaliação negativa de sua existência, um "(...) olhar que é reatualizado cada vez que o sujeito enfrenta uma situação de rejeição e estigmatização" (p. 57). Portanto, não é, necessariamente, a questão econômica que estabelece uma relação de dominação como esta, as relações sociais e profissionais também são relações poderosas de dominação, nas quais certos aspectos simbólicos têm predominância. A revalorização e o reconhecimento da importância deste grupo é uma necessidade primordial para que consigam conquistar ou reconquistar um lugar no seio de uma sociedade e da instituição em que são "mal vistos". Dessa forma, ainda de acordo com o autor, vão se estabelecendo mecanismos que definirão o grupo ou sujeito que será ou não investido de valor, "(...) a desqualificação social os levam a internalizar uma imagem negativa de si que, pouco a pouco, destrói do interior não apenas a revolta, mas também sua capacidade de ação" (p. 16). 
$\mathrm{Na}$ visão de Bourdieu (2003), esses sujeitos podem ser considerados como vítimas estruturais, cujo sofrimento seria provocado pelas contradições, incoerências e ambigüidades das instituições. Segundo Dejours (citado por Gaulejac, 2006), o sofrimento psíquico no trabalho surgiria quando a relação entre o desejo do indivíduo e a organização do trabalho é bloqueada, existindo uma defasagem entre a organização recomendada e a real, o que deixaria os trabalhadores em tensão. $\mathrm{O}$ uso do álcool talvez seja um dos meios deles escaparem a estas contradições, exigências contraditórias, tensões e incoerências no trabalho, vividas em silêncio, muitas vezes por resignação.

Aproximando-se do grupo dos excluídos, espera-se que os pacientes do CEDEQ se recuperem de um problema que é compreendido pela instituição naval como sendo exclusivamente deles, transformando-se em depositários de variadas mazelas, muitas das quais não lhes pertencem. Este processo de exclusão reproduz o que se verifica no mundo moderno, onde se observa o surgimento de uma progressiva demarcação entre o que será incluído e o que ficará excluído, estabelecendo-se uma linha de fronteira entre o normal e o patológico, o aceito e o rejeitado. Os alcoolistas do CEDEQ parecem constituir um núcleo no qual essa realidade se atualiza, composto de sujeitos que, de alguma forma, não se adequaram às exigências institucionais e expectativas da sociedade, muitas delas relacionadas, em seu âmago, aos pressupostos capitalistas de produtividade, devendo ser afastados. Nos navios, quando um militar apresenta problemas com o álcool que venham a se tornar perceptíveis ao Comando, ele é expurgado, sendo desembarcado, geralmente, para a Base Naval do Rio de Janeiro, uma organização militar que tem o perfil de, tradicionalmente, abrigar pessoas problemáticas. $\mathrm{O}$ afastamento é a solução clássica aplicada pelos administradores navais. Embora os militares não façam parte da engrenagem que produzirá diretamente os bens de consumo, cabe-lhes a proteção do bom funcionamento destas engrenagens de modo a não serem interrompidas. Porém, quando não conseguem corresponder a esta expectativa, quando não têm sucesso em se manterem hígidos, quando, conseqüentemente, deixam de representar a força que a instituição militar precisa ostentar, enfraquecem o pilar de sustentação da ideologia da modernidade, devendo ser afastados, transformando-se em refugos humanos, conforme Bauman (2005) salienta. Destoando da aparente homogeneidade da tripulação naval, os alcoolistas do CEDEQ aproximam-se, perigosamente, do grupo dos excluídos criando um contingente de refugos humanos.

A 'sociedade organizada' trata-os como parasitas e intrusos, acusa-os, na melhor das hipóteses, de simulação e indolência, e, freqüentemente, de toda espécie de iniqüidades, como tramar, trapacear, viver à beira da criminalidade, mas sempre de se alimentarem parasitariamente do corpo social (Borges citado por Bauman, 2005, p. 55).

A criminalização de segmentos da população identificados como marginais ou como refugos humanos é um processo que faz parte deste sistema, que vai estipulando, por meio de seus regulamentos, normas e crenças, quais os sujeitos que farão parte deste contingente.

Nesse cenário, o uso do álcool parece surgir como possibilidade de expansão do sujeito, ignorado no dia-a-dia. No bar, a branquinha (cachaça) é promessa de libertação, ainda que provisória, de sua fala, desfazendo a sua mudez contingencial. Porém, trata-se de uma fala parcial, circunscrita aos efeitos inebriantes que desafogam emoções. Uma parcela de seu ser permanece em silêncio. Para lidar com sentimentos de exclusão, ele busca o apoio dos campanhas (colegas de farda), criando oportunidades de beber, pois a alcoolização é uma prática de socialização. Pelo copo, ele realiza seus desejos, tornando o beber sua principal e, muitas vezes, sua única solução/realização. O botequim surge como local privilegiado de descontração para os militares, aliviando sentimentos de exclusão, frustração e de sofrimento, como um "oásis". Mergulhado em uma sociedade problemática, ele se defronta com a tarefa hercúlea de se sobrepor às pressões diárias que sofre, sendo testado a cada esquina, quando fica magnetizado pelos sedutores outdoors, estampados com imagens sedutoras de copos gelados, 
oferecidos por eletrizantes mulheres. "À magia das palavras, a contemporaneidade acrescentou o fascínio mágico das imagens produzidas por novíssimas tecnologias, com efeitos de ilusionismo e demagogia semelhantes aos obtidos com a velha adulação (kolakeia) da sofística" (Sodré, 1996, p. 23). Patrocinada por uma mídia que sustenta a popularidade do álcool e que assegura a sua livre circulação e acesso, o consumo do álcool vai se tornando uma prática "compulsória", imputada pelas regras de sociabilidade da atualidade, tornando ainda mais árduo o desafio do alcoólico de se sobrepor ao vício.

\section{Conclusão}

Embora predomine o foco nas abordagens terapêuticas e nas medidas administrativas voltadas às subjetividades dos militares que são pacientes do CEDEQ, reconhece-se a relevância de se considerar os aspectos institucionais na determinação do seu alcoolismo. Destacou-se, neste estudo, a fácil disponibilidade do álcool no seio institucional, sobretudo em razão da existência de uma cultura e tradição navais que são favoráveis ao seu consumo, facilitando o seu uso pesado. Portanto, estes sujeitos podem ser considerados como vítimas estruturais, cujo sofrimento seria provocado pelas contradições, incoerências e ambigüidades da organização militar naval.

Constatou-se ainda que o alcoolismo é um transtorno multideterminado, sendo, na realidade, construído socialmente. Essa concepção permite a compreensão de que devam existir aspectos laborais, em cada organização, que colaborem para o sofrimento do trabalhador, participando da determinação de seu alcoolismo. Por conseguinte, os pacientes militares alcoolistas do CEDEQ denunciam a existência de um mal-estar, não apenas pessoal ou familiar, mas institucional. Sua ocorrência convida a que sejam feitas maiores investigações no intuito de se conhecer os fatores laborais que podem provocar impactos na saúde destes trabalhadores, visando a implementação de ações profiláticas e preventivas junto ao contingente naval.

\section{Referências}

Ames, G. M. \& Janes, C. (1992). Cultural approach to conceptualizing alcohol and the workplace. Alcohol Health $\mathbb{E}$ Research World, 16 (2), 112-119.

Ames, G. M., Grube, J. W. \& Moore, R. S. (1997). Relationship of drinking and hangovers to workplace problems: an empirical study. Journal of Studies on Alcohol, 58 (1), 37-47.

Ames, G. M. \& Grube, J. (1999). Alcohol availability and workplace drinking: mixed method analyses. Journal of Studies on Alcohol, 60 (3), 383-393.

Ames, G. M., Baraban, E. A., Cunradi, C. B. \& Moore, R. S. (2004). A longitudinal study of drinking behavior among young adults in the military. Paper presented at the Research Society on Alcoholism Annual Scientific Meeting, Vancouver, BC.

Ames, G. M. \& Cunradi, C. B. (2005). Alcohol use and preventing alcohol-related problems among young adults in the military. Alcohol Research $\mathcal{E}$ Health, 28 (4), 252-257.

Bauman, Z. (2005). Vidas desperdiçadas. Rio de Janeiro: Zahar.

Berger, P. L. \& Luckmann, T. (1985). A construção social da realidade: tratado de sociologia do conhecimento. Petrópolis: Vozes.

Bourdieu, P. (2003). A miséria do mundo. Petrópolis: Vozes.

Bourdieu, P. (2007). O poder simbólico. Rio de Janeiro: Bertrand. 
Brasil (1996). Decreto n. 88.545, de 26 de julho de 1983. Artigo 7º Aprova o regulamento disciplinar para a Marinha e dá outras providências. Rio de Janeiro: Serviço de Documentação da Marinha.

Camargo Júnior, K. R. (1992). (Ir)racionalidade médica: os paradoxos da clínica. Physis, Revista de Saúde Coletiva, 2 (1), 203-227.

Cruz, M. S. \& Ferreira, S. M. B. (2001). Determinantes socioculturais do uso abusivo de álcool e outras drogas: uma visão panorâmica. In M. S. Cruz \& S. M. B. Ferreira (Orgs.), Álcool e drogas: usos, dependência e tratamentos (pp. 95-114). Rio de Janeiro: IPUB/CUCA.

Gaulejac, V. de (2006). As origens da vergonha. São Paulo: Via Lettera.

Grube, J. L., Ames, G. M. \& Delaney, W. (1994). Alcohol expectancies and workplace drinking. Journal of Applied Social Psychology, 24, 646-660.

Gruenwald, P. J., Millar, A. B. \& Treno, A. J. (1993). Alcohol availability and the ecology of drinking behavior. Alcohol Health E Research World, 17 (1), 39-45.

Kuhn, T. (1991). A estrutura das revoluções científicas. São Paulo: Perspectiva.

Luz, M. T. (1992). I Seminário do projeto racionalidades médicas. Rio de Janeiro: IMS/UERJ.

Luz, M. T. (1996). A arte de curar versus a ciência das doenças: história social da homeopatia no Brasil. São Paulo: Dynamis.

Moore, R. S., Ames, G. M. \& Cunradi, C. B. (2007). Physical and social availability of alcohol for young enlisted naval personnel in and around home port. Substance Abuse Treatment, Prevention, and Policy, 2 (17).

Pack, A. J. (1982/1995). Nelson's blood: the story of naval rum. Stroud: Alan Sutton.

Santos, F. S. D. (2006). Bêbados e alcoólatras, medicina e cotidiano. In D. R. Nascimento, D. M. Carvalho \& R. C. Marques (Orgs.), Uma história brasileira das doenças (vol. 2, pp. 64-91). Rio de Janeiro: Mauad.

Seligmann-Silva, E. (1990). Saúde mental e trabalho. In N. do R. Costa \& S. Tundis (Orgs.), Cidadania e loucura: políticas de saúde mental no Brasil (pp. 217-287). Petrópolis: Editora Vozes/Abrasco.

Seligmann-Silva, E. (1995). Psicopatologia e psicodinâmica no trabalho. In R. Mendes (Org.), Patologia do trabalho (pp. 287-310). Rio de Janeiro: Atheneu.

Silva Filho, J. F. \& Luce, C. (2001). O declínio do pai, a mimesis e a toxicomania. In M. S. Cruz \& S. M. B. Ferreira (Orgs.), Álcool e drogas: usos, dependência e tratamentos (pp. 63-76). Rio de Janeiro: IPUB/CUCA.

Sodré, N. W. (1965). História militar do Brasil. Rio de Janeiro: Civilização Brasileira.

Vaissman, M. (2004). Alcoolismo no trabalho. Rio de Janeiro: Garamond.

\section{Endereço para correspondência} espindolahalpern@yahoo.com.br

Recebido em: 19/05/2008

Aprovado em: 18/07/2008 